1 The role of habitat and daily activity patterns in explaining the diversity of mountain

2 Neotropical dung beetle assemblages

3

4 Pedro Giovâni da Silva ${ }^{1 \dagger}$

5 Jorge M. Lobo ${ }^{2}$

6 Malva Isabel Medina Hernández ${ }^{1}$

7

8 Programa de Pós-Graduação em Ecologia, Universidade Federal de Santa Catarina,

9 Florianópolis, Santa Catarina, Brazil

10 2Depto. de Biogeografía y Cambio Global, Museo Nacional de Ciencias Naturales, C.S.I.C.,

11 Madrid, Spain

12

13 Short-title: Drivers of dung beetle daily patterns

14

\title{
Correspondence
}

16 Pedro Giovâni da Silva

17 Programa de Pós-Graduação em Ecologia, Conservação e Manejo da Vida Silvestre,

18 Universidade Federal de Minas Gerais, 31270-910, Belo Horizonte, Minas Gerais, Brazil

19 E-mail: pedrogiovanidasilva@yahoo.com.br

20 Tel.: +55 (31) 971402486

21

22 † Current address: Programa de Pós-Graduação em Ecologia, Conservação e Manejo da Vida

23 Silvestre, Universidade Federal de Minas Gerais, 31270-910, Belo Horizonte, Minas Gerais,

24 Brazil 
26 Acknowledgments We would like to thank Franciéle Garcês for helping during fieldwork,

27 Dr. Fernando Vaz-de-Mello for dung beetle identification, Dr. Eduardo Giehl for insights on 28 some analyses, and reviewers for valuable suggestions. We also thank the Instituto Chico

29 Mendes de Conservação da Biodiversidade for permission to collect beetles and for logistical 30 support at the São Joaquim National Park. We thank the Ciências Sem Fronteiras program of 31 the Ministério da Educação via Coordenação de Aperfeiçoamento de Pessoal de Nível 32 Superior - CAPES (Process 88881.068089/2014-01) for financial support. PGdS would like 33 to thank CAPES for a Post-doctoral grant (Process 88881.068089/2014-01) and MIMH 34 thanks the Conselho Nacional de Desenvolvimento Científico e Tecnológico (CNPq) for a 35 Productivity grant (Process 309030/2013-7). 


\section{The role of habitat and daily activity patterns in explaining the diversity of mountain}

\section{Neotropical dung beetle assemblages} (1)

Abstract The interaction between land use and climate change is expected to strongly affect species distributions along high elevation landscapes. We aimed to test the effect of climatic variables on community metrics among five types of land use in a high elevation landscape. We described dung beetle spatial and temporal taxonomic and functional diversity patterns, and partitioned $\beta$-diversity into turnover and nestedness components. The interaction between land use and daily period of activity mostly drives abundance, functional richness, and functional diversity, but not dung beetle species richness. Unlike Neotropical lowlands, species richness and abundance in open environments are similar to those existing in forests. Temperature is an important predictor of abundance and functional divergence. There is a higher spatial component of the taxonomic $\beta$-diversity, which is highly driven by species turnover. The temporal component of the taxonomic $\beta$-diversity was strongly driven by nestedness, where night assemblages are sub-sets, although not entirely, of diurnal assemblages. For functional diversity, the temporal $\beta$-diversity was much higher than the spatial $\beta$-diversity, but both were similarly represented by functional group turnover and nestedness. The composition of nocturnal and diurnal assemblages is clearly different, even more than the differences observed between habitats. However, taxonomic turnover is the dominant force between sampling sites while nestedness dominates the daily pattern. This means that forest habitats are unlikely to act as shelters for grassland species under a scenario of rising temperature.

Keywords. Functional diversity, Scarabaeinae, spatial pattern, taxonomic diversity, temporal pattern. 


\section{Introduction}

Habitat changes such as conversion, degradation, and habitat loss due to human activities are causing global biodiversity declines (Tittensor et al. 2014). However, the local response by biodiversity to these changes are less clear but can be very useful to predict global biodiversity responses. Although many of the main drivers of biodiversity loss are detected at the global scale, the most important pressure mechanisms generally act more locally (Brook et al. 2013).

Locally, the climate experienced by a species is a key determinant of population growth and an important variable of the fundamental niche space (Hutchinson 1957). Microclimates can differ markedly between different types of habitats (Geiger et al. 2003), where forest cover substantially reduces solar radiation at the soil and lowers the temperature compared to open environments (Oliver \& Morecroft 2014). Moreover, there also is a buffering effect between ambient and soil temperatures; while surface temperature is cooler during temperature peaks, it is warmer at night in closed environments compared to grasslands (Suggitt et al. 2011). Changes in land use are also expected to be a major biodiversity driver near the tropics, while the temperature change is expected to have higher importance towards the poles (Jetz et al. 2007). Therefore, studies attempting to unveil the interacting effects of land use and temperature on biodiversity patterns are needed urgently (Oliver \& Morecroft 2014) to understand the probable buffering capacity of habitat on temperature effects, especially in the current scenario of global warming (Frey et al. 2016). Temperature has a strong impact on species distributions, especially in poikilothermic or heterothermic insects, such as dung beetles (Schowalter 2011). Dung beetles (Coleoptera: Scarabaeinae) comprise a diverse group of dung and detritus-feeding insects that play a key role in important ecological processes such as decomposition, secondary seed dispersal, and nutrient recycling (Nichols et al. 2008). They have long been used as good models to 
investigate applied and theoretical issues in ecology and conservation because their assemblages are negatively affected by both natural and anthropogenic environmental changes (Nichols et al. 2007). In tropical biomes, several scarabaeine beetles are forestdependent and unable to extend their populations to open areas (Klein 1989), probably due to climatic and resource limitations. Both temperature and precipitation are also known to affect dung beetle distribution spatially and temporally (Hernández \& Vaz-de-Mello 2009; Liberal et al. 2011; da Silva et al. 2013).

Nesting behaviour and body size have been acknowledged to affect dung beetle ecological functions (Slade et al. 2007). There is strong evidence of the negative impacts on ecosystem functioning due to the loss of some dung beetle traits in human-driven environments (Braga et al. 2013). Tropical primary forests host large dung beetles and body size decreases among individuals of different genera outside this habitat (Gardner et al. 2008). Daily activity can also be an important trait since climatic conditions can drive the daily and seasonal activity of dung beetles in environments with extreme climates, having a spatial and temporal effect on the diversity and distribution of species. Therefore, gathering relevant traits are needed for a better understanding of the mechanisms driving the spatiotemporal distribution of species.

As opposed to Palearctic temperate biomes (Hanski \& Cambefort 1991; Lobo et al. 1998), there is a huge body of evidence that dung beetle diversity is higher in Neotropical forests than in open environments (either natural or artificial) (Scheffler 2005; Gardner et al. 2008). A decline in dung beetle ecosystem functions and services is also well documented along those habitat gradients (Braga et al. 2013; Batilani-Filho \& Hernández 2017). However, there is little information specific to the dung beetle response to changes in human-driven land uses along high elevational Neotropical landscapes (Arellano et al. 2005; AguilarAmuchastegui \& Henebry 2007). In these systems, there is a wide variation in daily and 
114 seasonal climatic conditions, which can have different effects on dung beetles depending on

115 the type of land use. Dung beetles also seem capable of using incident radiation differently in 116 order to gain the necessary body heat (Amore et al. 2017). Thus, unlike tropical lowlands,

117 under the relatively cold conditions of tropical mountain areas, some species might prefer

118 open environments to acquire the body temperature required for their activities.

119 Dung beetles can also show differential daily activity patterns (Landin 1968; Koskela

120 1979; Krell-Westerwalbesloh et al. 2004; Iannuzzi et al. 2016) probably linked with the

121 capacity of thermoregulation and the management of body temperature (Verdú et al. 2004;

122 Gallego et al. 2018; Giménez-Gómez et al. in press). Thus, it might be expected that night

123 dung beetle assemblages may be a small sub-sample of day assemblages inhabiting

124 temperate-cold conditions in the Neotropical region; i.e. assemblages composed of those

125 species able to deal with low temperatures. However, it may also be possible that closed

126 habitats (e.g. forests) could have buffered temperatures, and therefore, harbour higher species

127 richness and abundance values than open environments (e.g. grasslands) at night, thus being

128 able to act as thermal shelters harbouring species with different functional traits as those

129 present in grasslands. For example, body size can be an essential trait to gain body heat, and

130 roller dung beetles, which roll food-balls above the ground away from the resource, could be

131 more affected by environmental conditions than tunneler species that are more related to soil

132 conditions due to their nesting strategy.

133 In this study, we examine the differences in species richness, abundance, and

134 taxonomic or functional composition among five sites with different land uses along day-

135 night sampling periods at a high elevation landscape in southern Brazil. Day and night dung

136 beetle assemblages were sampled in five sites along a closed-open gradient: primary forest,

137 secondary forest, agroforest, shrubland, and grassland. The main purposes of these

138 comparisons are to assess i) if the general decreasing pattern in dung beetle diversity 
139 established for open habitats when compared to forests is maintained when these habitats are

140 located in cold mountainous subtropical regions, and ii) how taxonomic and functional

141 composition of dung beetle assemblages vary with the daily period depending of the habitat

142 type. Additionally, since functional and compositional differences between habitats and daily

143 periods can be due to the replacement (turnover) or gain/loss (nestedness) of species, we

144 estimate the comparative relevance of these two patterns on spatial and temporal assemblage

145 differences because they would have different implications for the shelter role played by

146 forest under an increasing temperature scenario.

\section{Methods}

149 Study area

150 The study was performed in a landscape composed of five different types of land uses (called 151 sites from now on; Table S1) in the São Joaquim National Park, a Federal Conservation Unit 152 located in the state of Santa Catarina, southern Brazil $\left(28^{\circ} 05^{\prime}-28^{\circ} 20^{\prime} \mathrm{S}, 49^{\circ} 21^{\prime}-49^{\circ} 39^{\prime} \mathrm{W}\right)$.

153 This conservation unit was created to preserve the Araucaria angustifolia forest (also called

154 Mixed Ombrophilous Forest) and high-altitude grasslands located in the Serra Geral

155 mountainous formation. Since the park is located at the top of a mountainous region, there is a 156 wide variation in temperature, ranging from negative temperatures in the winter to near $40^{\circ} \mathrm{C}$ 157 in the summer.

158 The five sampled sites included primary forest, secondary forest, shrubland,

159 agroforest, and grassland. Primary and secondary forests were characterized by the presence

160 of A. angustifolia with differences in timber harvesting, where the secondary forest suffered 161 selective cutting and has been regenerating for 30-40 years. The shrubland is characterized by

162 isolated trees (A. angustifolia) and a high density of Baccharis uncinella (Asteraceae), a

163 phanerophyte and woody bush that can reach up to $2 \mathrm{~m}$ in height. The grassland consists of 
164 species such as Andropogon lateralis (Poaceae) and Baccharis articulata (Asteraceae), and no

165 trees. Two horses were present in this site during the previous months. The agroforest was

166 composed of both forest and grassland biotic components, with the presence of $A$.

167 angustifolia. The understory is open and grasslands dominate the soil. During the previous

168 months, the cattle herd consisted of about 10 cows and 5 horses. The grassland and agroforest

169 were human-modified land uses, since both were previously A. angustifolia forests.

$170 \quad$ All sites were located at ca. $1300 \mathrm{~m}$ a.s.1. and with a mean distance of $280( \pm 103 \mathrm{sd}) \mathrm{m}$

171 between each other. The small distance between the sampling sites is characteristic of the

172 studied landscape. This distance does not limit the colonization and dispersion of the species

173 between sampling sites and, at the same time, is enough to ensure their independence

174 character during the period of study (see da Silva \& Hernández 2015b). Since the objective of

175 this study was not to obtain results which can be extrapolated to a particular situation (i.e.

176 grasslands vs. forests) we did not include replicates of each habitat type (Peyras et al. 2013).

177 Instead, as our objective was to explore the response of species and assemblages to daily

178 periods in series of contrasting habitats, we decided to maximize the number of different

179 habitat in the landscape instead of replicating particular sites (Peyras et al. 2013).

180

181 Sampling design

182 Dung beetles were sampled using baited pitfall traps. These traps were made with plastic

183 containers (15 cm diameter x $20 \mathrm{~cm}$ depth) buried with the top edge at ground level, a rain

184 protector, and a mixture $(300 \mathrm{ml})$ of water and neutral detergent to prevent the escape of

185 beetles. As bait, human faeces and rotting flesh (aged in plastic containers at room

186 temperature three days prior to sampling) were used separately (ca. $20 \mathrm{~g}$ of each) to attract

187 copronecrophagous dung beetles. 
Each sampling site contained five pairs of traps spaced 5-10 m apart. Each pair contained both kinds of bait and was considered a sampling unit (the data from each pair were pooled and considered as a sampling unit). The pairs were spaced $100 \mathrm{~m}$ apart assuming that this distance is enough to promote independence independently of the vegetation structure (da Silva \& Hernández 2015b). The traps remain in the field for a total of 48 h (da Silva \& Hernández 2014). The study was conducted in January 2017, which is summer in the region, a period of high richness and abundance of dung beetles in southern Brazil (Hernández \& Vazde-Mello 2009; da Silva et al. 2013).

We obtained four samples during the study period to characterize diurnal and nocturnal dung beetle assemblages. On day one, we installed the traps in all sampling sites between 6:00-7:30 in the morning. All beetles sampled during the day were removed between 18:30-20:00 h. The next morning, between 6:00-7:30 h, all beetles sampled during the night were removed and the baits renewed. The same was done for day two, totalling two samples of diurnal and two samples of nocturnal dung beetles in each sampling site. Thus, in total, we managed information coming from 100 samplings units (5 sampling units $\mathrm{x} 5$ sites $\mathrm{x} 2$ days $\mathrm{x}$ 2 periods). The beetles collected were sorted, identified, and conserved in $70 \%$ alcohol. An expert, Dr. Fernando Vaz-de-Mello (Universidade Federal de Mato Grosso, Brazil), confirmed species identifications. The beetles were deposited in the Entomological Collection of the Universidade Federal de Santa Catarina, and the Zoological Collection of the Universidade Federal de Mato Grosso, Brazil.

\section{Dung beetle attributes}

In order to characterize dung beetle functional attributes, all species were grouped according to their nesting behaviour (tunneler, roller or dweller), daily activity (diurnal, nocturnal or diurnal-nocturnal), and body size (small and large-sized). Nesting behaviour was attributed 
213 according to the literature (Halffter \& Edmonds 1982; da Silva \& Hernández 2015a). Daily

214 activity (diurnal or nocturnal species) was attributed following the criteria of $\geq 95 \%$ of

215 individuals sampled in one daily period of activity. Species with a similar number sampled in

216 both periods were grouped as diurnal-nocturnal species. Data from literature was also

217 consulted for species with less than 10 individuals to corroborate the species grouping

218 (Hernández 2002; Lopes et al. 2011; da Silva \& Hernández 2015a). Species with less than 1

$219 \mathrm{~cm}$ in length were grouped as small-sized, while species with a length $\geq 1 \mathrm{~cm}$ were grouped as 220 large-sized (Escobar et al. 2008).

Climatic predictors

223 To characterize the climatic conditions experienced by dung beetles during day and night, we

224 used data loggers to record measurements of temperature at $15 \mathrm{~min}$ intervals during the

225 samplings. We installed two dataloggers at the third sampling point in each site, the first at 1

$226 \mathrm{~m}$ above the soil (in a shaded location) and the other buried in the soil $(5 \mathrm{~cm})$. Additionally,

227 we installed a pluviometer to record the rain during the samplings.

228 Using the temperature measurements, we calculated mean, minimum, maximum, and

229 range of temperature for each sampling period (two days and two nights separately), for both

230 ambient and soil. After standardization of all these climatic variables to eliminate the effect of

231 measurement scale differences (to a mean of zero and standard deviation of one), they were

232 subjected to a Principal Component Analysis to select those uncorrelated. Three uncorrelated

233 components with eigenvalues higher than one were obtained and together were able to explain

$23491.4 \%$ of the total variability $(50.7 \%, 24.7 \%$, and $16.0 \%$, respectively). Three variables with

235 the highest factor loadings (fl) were selected for each of the components: minimum ambient

236 temperature for the first PCA component $(\mathrm{fl}=0.946)$, maximum soil temperature for the

237 second PCA component $(\mathrm{fl}=0.900)$, and precipitation for the third PCA component $(\mathrm{fl}=$ - 
0.875). These three climatic predictors were selected as co-variables in order to assess the differences in biodiversity measurements between sampling sites (primary forest, secondary forest, agroforest, shrubland, and grassland) and daily period of activity (day or night) when the effect of these climatic predictors was controlled (see Fig. S1).

\section{Statistical analyses}

We first estimate the completeness of the obtained assemblages by calculating the final slope (coverage) of the species accumulation curves relating the increase in the number of species with the addition of individuals. To do that, the function "iNEXT" of the R package "iNEXT" was used (Hsieh et al. 2016). Additionally, the Chaol non-parametric estimator (Chao 1984) was also calculated to estimate the "true" number of species in each site taking into account the number of species represented by just one or two individuals (singletons and doubletons). These calculations were conducted with the sole aim of assuring that the comparison of the obtained assemblages is not excessively biased.

Besides species richness and abundance of dung beetles, we used two metrics able to represent different aspects of functional diversity: functional richness (FRic) and functional divergence measured by using the Rao quadratic entropy (Rao's Q). FRic represents simply the number of unique trait combinations (Villéger et al. 2008), while Rao's $Q$ characterizes the dispersion of species in the trait space weighted by their relative abundance (Laliberté \& Legendre 2010). The complementary use of these two functional metrics allow us to examine the between-site differences in the number of functional attributes that the collected species possess, but also to compare the degree of functional variability present in each site. FRic was measured for each period using all sampling sites and the "dbFD" function of the R package “FD” (Laliberté et al. 2014). To estimate Rao’s $Q$ a species dissimilarity matrix was first created based on the formerly described functional attributes by using the "Gower approach" 
263 from the "trova" function (see de Bello et al. (2013) for details) for R software on the data of 264 each sampling period and sampling site. We used the "Rao" R function (de Bello et al. 2009) 265 that calculates the Rao quadratic entropy taking into account Jost's correction (Jost 2007). 266 This metric represents the number of equivalent species (in terms of abundance) sharing no 267 functional traits (minimum value $=1$ ) and is maximal when all species in a sampling unit are 268 maximally dissimilar and have equal abundances (Nunes et al. 2016). FRic and Rao's $Q$ are 269 not correlated (Pearson's correlation $=0.32, t=1.427, p=0.170$ ). Generalized Linear Mixed Models (GLMMs) were used to estimate whether the four 271 response variables (species richness, abundance (in Log), FRic, and Rao’s Q) significantly

272 vary between the five sampling sites (spatial scale) and the two daily periods of activity 273 (temporal scale). The effect of these two categorical factors on these response variables was 274 evaluated, including the interaction between them (sampling sites $\mathrm{x}$ daily periods), as well as 275 the three formerly selected climatic variables as covariates. Since we did not have replicates 276 of sites, we used the traps as sample units repeatedly sampled over two days and two nights at 277 the same site. We, therefore, included traps and sampling periods as random factors to 278 account for pseudoreplication. The GLMMs were ran using the function "glmer", "glmer.nb", 279 and "Imer" of the R package "Ime4" (Bates et al. 2015) for Rao's Q (Gaussian distribution), 280 abundance (negative binomial distribution), and species and functional richness (both using 281 Poisson distribution), respectively. As two sites can have similar species richness, abundances and functional diversity 283 values, but may differ in their faunistic compositions, additional analyses were carried out to 284 examine the compositional changes between sampling sites and daily periods $(\mathrm{N}=20)$. This 285 has been done by calculating a permutational multivariate analysis of variance 286 (PERMANOVA; (Anderson 2001); a non-parametric multivariate statistical test used to 287 analyse differences between two or more groups or factors (and their possible interactions) 
based on any distance or similarity measure. The Jaccard coefficient was used to perform the similarity matrix and the "adonis" function of the "vegan" R package (Oksanen et al. 2016) used to carry out calculate PERMANOVA tests. The so obtained results were graphically depicted by using a non-metric multidimensional scaling (NMDS) representation.

Some complementary analyses have been carried out in order to discriminate the comparative role of the two studied scales (spatial or daily) in explaining the taxonomic and functional composition of the complete regional dung beetle assemblage. To do this, an analysis of additive partitioning of diversity $(\beta=\gamma-\alpha)$ was used. The taxonomic alpha diversity $(\alpha)$ represents species richness by sampling site per daily period of activity, while the functional $\alpha$ diversity represents the number of equivalent species (in terms of abundance) sharing no functional traits (minimum value $=1$ ). The taxonomic beta diversity $(\beta)$ represents the composition differences between sampling site per daily period, while functional $\beta$ diversity represents the addition of new functional diversity when pooling different communities together. Finally, the taxonomic gamma diversity $(\gamma)$ represents the total species richness of all sites sampled, while the functional $\gamma$ diversity represents the total functional diversity of all sites sampled. Therefore, we will have two $\alpha, \beta$, and $\gamma$ diversity values, one representing the spatial scale $\left(\beta_{S}=\gamma_{S}-\alpha_{S}\right)$ and the second representing the daily activity scale $\left(\beta_{\mathrm{T}}=\gamma_{\mathrm{T}}-\alpha_{\mathrm{T}}\right)$. For taxonomic diversity, we used the function "adipart" of the "vegan" $\mathrm{R}$ package (Oksanen et al. 2016), performing 999 permutations to test for statistical differences between observed and expected values of $\alpha, \beta$ (spatial and temporal), and $\gamma$ diversity at random. The Rao's $Q$ function described earlier also provides the partition of $\alpha, \beta$, and $\gamma$ functional diversity components, which provides standardized results to compare the partition of different facets of diversity (i.e. taxonomic and functional) (de Bello et al. 2009). Using the hierarchical null model test, performed by the "hiersimu" function of the "vegan" R package, we used the same levels as the "adipart" $\mathrm{R}$ function to test the functional diversity partitioning 
among spatial and temporal scales with 999 permutations. It allowed us to test for statistical

differences between observed and expected values of $\alpha, \beta$ (spatial and temporal), and $\gamma$ functional diversity at random.

Finally, the difference in diversity (both taxonomic and functional) between sampling sites (spatial $\beta$ ) or along the daily periods of activity (temporal $\beta$ ) can be due to species turnover (species replacement) or nestedness (species gain or loss) (Baselga 2010). An analysis of $\beta$ diversity partitioning was performed to test if the spatial and temporal $\beta$ diversities are due to species substitution or gain/loss, using the "beta.multi" function for taxonomic diversity and "functional.beta.multi" for functional diversity from the "betapart" $\mathrm{R}$ package (Baselga \& Orme 2012) and the Jaccard coefficient for both diversities. For functional diversity, we first performed a principal coordinate analysis (PCoA) on a Gower dissimilarity matrix of species traits, using the "pcoa" function of the "ape" R package with the "Lingoes" correction for negative values (Legendre \& Legendre 2012). The PCoA eigenvectors were then used to calculate functional turnover and nestedness since this transformation preserves the original distance among objects. As the proximity between the sampling sites may be affecting these calculations, we calculated Euclidean distances among sample units and used Mantel tests (with 999 permutations) to correlate $\beta$ diversity metrics and geographic distance. To do that, the "beta.pair" function of the "betapart" package was used calculating pairwise Jaccard dissimilarity (1-similarity), turnover, and nestedness values among samples to test if there is a spatial autocorrelation due to the relatively small distance among sampling sites.

\section{Results}

We sampled 1,428 individuals belonging to 19 species (Table S2). The values of sample coverage for the five sites were high, ranging between 0.992 and 1.000, except in the case of 
338 the grassland site (0.988) (Table S2). Thus, the probable total number of species hardly differs

339 from the one observed for most sites, except in the case of grassland where eight more species

340 could be expected according to Chao1 estimator (Table S2). Species richness ranged between

$341 \quad 10$ and 15 species, while abundance ranged between 202 and 377 individuals by sampling

342 site. A total of 18 species $(94.7 \%)$ were sampled during the day, while only nine species

$343(47.4 \%)$ were sampled during the night. We sampled 7.3 times more individuals $(\mathrm{N}=1257)$

344 during the day than at night $(\mathrm{N}=171)$. Among sampling sites, we sampled between 5 and 13

345 species (mean $8.6 \pm 2.8 \mathrm{sd}$ ) during the day, but only between 1 and 4 species (mean $2.9 \pm 1.3 \mathrm{sd}$ )

346 during the night. From all the species, only one (0.1\%) was a doubleton, while four (21.1\%)

347 were found in all sampled sites.

349 Species richness, abundance, and functional differences

350 The statistically significant interaction between sampling sites and daily activity period was

351 important to explain dung beetle abundance, functional richness, and functional divergence

352 (Rao's Q), but not species richness (Table 1). Species richness differed significantly only

353 between daily periods, with three times more individuals sampled per trap during the day, on

354 average (Fig. 1). There were more individuals sampled during the day for open grassland and 355 secondary forest (Fig. 2). Functional richness was lower in grassland and agroforest sites 356 (predominance of diurnal, small-sized rollers and tunnelers) and does not differ between day 357 and night except for the secondary forest site (Fig. 2). However, functional divergence seems 358 to be low in open sites but high in the forest at night, where a slightly opposed pattern appears 359 in the case of diurnal assemblages (Fig. 2). This pattern is found because of the occurrence of 360 the large-sized roller and both small- and large-sized tunneler species in the primary forest 361 site at night. The significant role of minimum ambient temperature reveals that a higher 
abundance and functional divergence can be obtained when the temperature increases (Table

1). Maximum soil temperature and precipitation did not affect any of the dung beetle metrics.

366 The interaction between sampling site and daily period did not significantly influence the 367 community composition of dung beetles in the studied system (PERMANOVA $F=1.602, p=$ 368 0.095). However, dung beetle composition changed between sampling sites (PERMANOVA $369 F=3.138, p=0.003, R^{2}=25.9 \%$; Fig. 3 ), but mainly between daily periods (PERMANOVA $370 F=19.554, p=0.001, R^{2}=40.3 \%$ ). No differences in the variances of the groups were found 371 by sampling site (PERMDISP $F=0.345, p=0.843$ ) or daily period (PERMDISP $F=4.137, p$ $372=0.056)$.

The role of site and daily periods in explaining the diversity

375 The mean taxonomic $\alpha$ diversity sampled for the daily period of activity at each site was 7.3

376 species, which was lower than expected by chance. The taxonomic $\beta$ diversity among 377 sampling sites (spatial scale) was higher than among daily periods (temporal scale). The 378 spatial component of taxonomic $\beta$ diversity was 2.3 times higher than expected by chance, 379 while the temporal component was similar to that expected by chance (Fig. 4a). At the spatial 380 scale, the dissimilarity among sampling sites was $64.4 \%$, mostly represented by species 381 turnover, which accounted for $87.7 \%$ of the value. The nestedness-related component only 382 accounted for $12.3 \%$ of the spatial $\beta$ diversity. However, at the temporal scale taxonomic $\beta$ 383 diversity was $57.9 \%$, mostly represented by species nestedness, which accounted for $65.5 \%$ of 384 the dissimilarity between day and night assemblages. The turnover component represented 385 only $34.5 \%$ of the temporal $\beta$ diversity (Fig. 4 b). There was no correlation between the 386 geographic distance among sampling sites and Jaccard dissimilarity (Mantel $\mathrm{r}=0.072, \mathrm{p}=$ 
0.114), species turnover (Mantel $\mathrm{r}=0.073, \mathrm{p}=0.164$ ), and the nestedness-related component of $\beta$ diversity (Mantel $r=-0.044, p=0.730$ ) (Fig. S2).

The functional $\gamma$ diversity was mostly composed of the temporal $\beta$ diversity of functional groups, which was 4.6 times higher than the spatial $\beta$ diversity of functional groups (Fig. 4c). All diversity components were different from what was expected by chance.

Functional $\alpha$ diversity was lower than the expected value, while both $\beta$ diversities were 17.8 and 38.5 times higher than the expected values for temporal and spatial functional $\beta$ diversities. Spatially, $\beta$ diversity was composed equally of functional turnover and nestedness among sampling sites. Temporally, the functional turnover was slightly higher than functional nestedness, accounting for $58.6 \%$ of the functional $\beta$ diversity in the day and night assemblages (Fig. 4d).

\section{Discussion}

Our results revealed that (i) there is no decreasing pattern in dung beetle richness and abundance in open habitats when compared to forests in a cold mountainous subtropical region. In addition, (ii) the interaction between habitat and daily period of activity mostly drives abundance, functional richness, and functional diversity, but not dung beetle species richness. (iii) There is a decrease in functional divergence along the open-closed gradient during the day and opposed pattern during the night. (iv) For taxonomic diversity, there is a high species turnover spatially, and a nested pattern temporally, where night assemblages are sub-sets, although not entirely, of daytime diurnal assemblages. (v) For functional diversity, the temporal $\beta$-diversity was much higher than the spatial $\beta$-diversity, but both were similarly represented by functional group turnover and nestedness. Finally, (vi) the composition of nocturnal and diurnal assemblages is clearly different, even more than the differences observed between habitats. 
413 design carried out, specifically due to the apparent short sampling period used to collect the

414 handled data ( $48 \mathrm{~h}$ pitfall traps placed during two days in a summer month). However, recent

415 results demonstrate (da Silva et al. 2018) that the surveyed period is the one in which a higher

416 species richness and abundance of dung beetles can be collected in this locality; around

$41771.4 \%$ of the total annual species richness can be collected in a short-term survey like the one

418 carried out. Therefore, dung beetle data coming from short-term samplings are used to

419 provide strongly supported results (e.g. Gardner et al. 2008; Solar et al. 2015). Nevertheless,

420 further studies may allow to corroborate the detected patterns and to determine the role played

421 by seasonal variations in these patterns.

Dung beetle diversity in Neotropical grasslands may depend on elevation

424 Unlike Neotropical lowlands (Klein 1989; Scheffler 2005), dung beetle species richness and

425 abundance in open environments located in the sampled tropical mountain are not

426 significantly lower than those existing in closed and forest habitats, as previously expected

427 (Hanski \& Cambefort 1991; Lobo et al. 1998). Moreover, taking into account the estimated

428 richness (Chao1), it is possible that human-driven grasslands have a high number of

429 undetected species according to the accomplished survey effort. In São Joaquim National

430 Park, there are records of several other dung beetle species not sampled in our study that can

431 be found in high altitude grasslands located above $1600 \mathrm{~m}$ a.s.1. (Vaz-de-Mello et al. 2014; da

432 Silva 2017). Therefore, the expected richness in open environments in this mountainous

433 landscape may be quite higher than in closed forests. Thus, Neotropical open habitats would

434 act as temperate ones facilitating an increase in taxonomic and functional diversity of dung

435 beetles, perhaps for historical reasons related to the relationship between high elevation

436 grasslands and Pampas biome (a grassland-dominated ecosystem found in southern Brazil, 
437 Uruguay, and eastern Argentina; see below) and/or evolutionary causes. Lowland dung beetle

438 lineages could have evolved to inhabit cold conditions existing in tropical high elevation

439 biomes by acquiring appropriate physiological mechanisms to manage their body temperature

440 mainly under diurnal situations (the so-called "vertical" colonization proposed by Lobo \&

441 Halffter (2000)).

443 The role of daily activity patterns

444 Species richness is substantially different between day and night, and there is a significantly

445 high number of individuals collected during the day in the grassland compared to closed

446 habitats. The grassland had the highest values of average temperature and temperature range

447 between day and night among all habitats, including temperatures below $15^{\circ} \mathrm{C}$ during the

448 summer nights (Fig. S1), which is considered a temperature where several dung beetle species

449 are unable to warm their flight muscles (Verdú et al. 2006). Furthermore, the maximum

450 temperature in some open sites reached $40-42^{\circ} \mathrm{C}$ (Fig. S1), a maximum tolerated temperature

451 that generates strong physiological flight constraints (Verdú et al. 2006). The maximum

452 temperature did not exceed $25-30^{\circ} \mathrm{C}$ in primary and secondary forests (Fig. S1), a temperature

453 range needed for successful and physiologically unconstrained flights in endothermic dung

454 beetles (Verdú et al. 2006). Three species dominated and accounted for $91.1 \%$ of the day

455 assemblages in grasslands: Dichotomius opalescens (44.4\%), Canthon seminitens (23.7\%),

456 and Canthon rutilans rutilans (23.1\%). These species are all colourful beetles (see Table S2),

457 and therefore, are expected to be diurnal (Hernández 2002), which our results corroborated. In

458 laboratory conditions, Amore et al. (2017) found that C. rutilans rutilans and D. opalescens

459 had low heating rates compared to lowland species, regardless the source of radiation

460 (infrared or simulated sun radiation). In addition, the heating rates of those species did not

461 differ from that found in Homocopris sp., a nocturnal, black-coloured dung beetle that 
462 inhabits primarily high elevation forests (Amore et al. 2017). These results suggest that, in

463 similar climatic conditions along the open-closed habitat gradient, both coloured and black

464 dung beetle species are able to reach similar internal temperatures and heating rates. However,

465 our results showed that temperature has different extreme values between open and closed

466 habitats considering day-night conditions. Therefore, due to differences in extreme

467 temperature values among sites, dung beetle species may require climate-driven conditions

468 that occur during different daily periods along the open-closed habitat gradient.

High abundances in open habitats during the day were also found by Iannuzzi et al.

470 (2016), who evaluated the daily activity of dung beetles in a northern tropical Atlantic Forest.

471 However, our results for forest habitats diverge from those found by these authors, who

472 sampled lower abundance in diurnal periods. Dung beetles tend to exhibit adaptations that

473 favour the occupation of both cooler and warmer periods of the day (Hernández 2002; Scholtz

474 et al. 2009; Amore et al. 2017), especially in landscapes with harsh climatic conditions, such

475 as mountainous regions. Since most dung beetles are poikilothermic, their small body size

476 assists in thermoregulation during the day, favouring both the gain (in cooler periods, such as

477 mornings) and exchange (in warmer periods, such as midday) of heat with the environment

478 (Feer \& Pincebourde 2005; Scholtz et al. 2009). In addition, rollers are expected to exploit the

479 resource more quickly than tunnelers to avoid strong competition and predation; thus, they

480 can overcome wind, luminosity, and temperature constraints in open environments (Krell et

481 al. 2003). The predominance of distinct functional groups among habitats increases the

482 landscape $\gamma$ diversity.

483 There was an increase in day-night functional richness along the extremes of the open-

484 closed gradient (two nocturnal, tunneler species found in the grassland and five roller and

485 tunneler species of small and large body size found in the forest at night). A similar pattern

486 was also found by Gómez-Cifuentes et al. (2017), who evaluated four types of land uses in 
relation to dung beetle functional richness and diversity in a northern Argentinean Atlantic Forest. However, this pattern was maintained only for night assemblages when using Rao functional divergence index. Our findings contradict those found by Barragan et al. (2011), who evaluated the functional diversity of dung beetles under different conditions of land use in three Mexican biosphere reserves, including pastures, forest fragments, and continuous rainforest. Values of functional measurements seem to be much more directly related to factors representing day-night and site variations than climatic predictors. This is also reflected by the high temporal functional $\beta$ diversity, where temporal and site characteristics exercise a strong influence on the functional diversity of dung beetle assemblages. Therefore, dung beetle functional response may vary depending on the daily period of activity but is independent of functional group richness for diurnal assemblages.

\section{Spatial and daily complementarity of dung beetles assemblages}

The faunistic composition of diurnal and nocturnal assemblages is clearly different, more so than the differences observed between sites. However, faunistic turnover is the dominant force between sampling sites while nestedness dominates the daily period of activity. Thus, although there are no differences in richness, there are different assemblages inhabiting each habitat. For example, only five species were shared between grassland and primary forest, with high contrasting patterns of abundance between these habitats (Table S2). Given the high contribution of species replacement among sites, our expectation that forest sites would be thermal shelters for grasslands species was not corroborated (see below) because each site have their own particular species. However, the relevance of nestedness patterns in daily variations indicates that there is a loss of species between day and night, where nocturnal assemblages are a fraction of diurnal assemblages, except in the case of Homocopris sp. and Uroxys terminalis, which seem to be almost exclusively nocturnal species (but related to 
512 forested sites). This change in species according to the daily activity does not have the same

513 effect on all functional groups. With the exception of Deltochilum brasiliense, all other rollers

514 are small-sized diurnal species. In nocturnal assemblages, there is a loss of both small-sized

515 rollers and small-sized tunnelers, represented by all species of Canthon and most species of

516 Canthidium. Another pattern found in our study is that the few species that inhabit forests are

517 functionally singular, while in pastures there are several redundant species. This finding is

518 contrary to Barragan et al. (2011), who found that in fragments and continuous forests most

519 species were redundant, with functional uniqueness found in pastures. Functional nestedness

520 was the main pattern among dung beetle assemblages along an elevational gradient in

521 southeast Brazil (Nunes et al. 2016), implying that there is a loss of functional diversity from

522 lowlands to highlands. Moreover, we show that both turnover and nestedness of functional

523 diversity of dung beetles similarly drive the daily pattern of these insects, with contrasting

524 responses among open and closed habitats. Dung beetles are a diverse dung and detritus-

525 feeding insect group that exhibits strong competitive behaviour for ephemeral food resources,

526 and therefore evolved different feeding and nesting strategies to avoid intraspecific and

527 interspecific competition and predation (Halffter \& Edmonds 1982; Hanski \& Cambefort

528 1991). Additionally, dung beetles perform their activities during different periods of the day

529 and year due to factors such as temperature and precipitation (Hanski \& Cambefort 1991).

530 The combination of spatial and temporal segregation and the complementarity of their

531 respective assemblages is attributed as one of the main factors driving the $\gamma$ diversity of this

532 group.

In our landscape, three species are forest-dependent, Canthon aff. luctuosus,

534 Deltochilum brasiliense, and Dichotomius aff. acuticornis, occurring only in secondary and

535 primary forests. All other species are matrix-tolerant species, but several of them are also

536 related to natural open ecosystems, such as high elevation grasslands and the Pampas biome, 
as found by da Silva (2017). This author highlights that $\sim 90 \%$ of the species found in high elevation grasslands in the São Joaquim National Park is shared with the Pampas. The high similarity found between these ecosystems is probably due to the biogeographic history of southern Brazil. Between 42-10 thousand years ago, cold, dry weather prevailed and the grassland formations dominated the region (Boldrini 2009). Between 10-4 thousand years ago, the temperatures increased, but the climate remained dry, thereby limiting the expansion of forest areas onto the grasslands. There is evidence of more frequent fires, which also slowed the advance of tree species (Behling et al. 2004). Four thousand years ago, when the climate became wetter, the Araucaria and Semidecidual forests began a gradual process of expansion over the grasslands, which became more significant around a thousand years ago (Behling et al. 2004). Nowadays, dung beetle fauna from both high elevation grasslands and Pampas are spatially segregated. With the arrival of humans, both Araucaria logging, as well as the introduction of livestock into open areas changed the landscape of the mountains in southern Brazil to become mosaics of different types of land use (Mello \& Peroni 2015).

\section{Conservation implications}

In the current scenario of global warming, the predicted future geographical distribution of the Araucaria forest based on a fundamental niche modelling (i.e. based on climate variables) shows a strong tendency to reduce their potential area in Brazil, especially in regions at lower latitudes and elevations (Wrege et al. 2017). The distribution of the Araucaria forest is strongly related to cooler temperatures and higher humidity in southern and southeast Brazil, covering areas up to $2400 \mathrm{~m}$ a.s.l. (Behling et al. 2004; Wrege et al. 2017). However, predicted scenarios of climate warming in South America suggest a great reduction in precipitation in the southeast of Brazil until 2100 (Chou et al. 2014). This scenario can severely affect the distribution of the Araucaria forest in our study region, where 
562 this forest formation does not surpass $1800 \mathrm{~m}$ a.s.1. (Behling et al. 2004). Although this forest

563 has undergone advances and retractions in its area of occurrence over time, such changes have

564 been relatively slow when compared to the current warming scenario (the predicted increase

565 in air temperature from $1.8^{\circ} \mathrm{C}$ to $6.3^{\circ} \mathrm{C}$ ) (Wrege et al. 2016). Therefore, for long life-cycle

566 species, such A. angustifolia, the process of adaptation should be much slower than expected

567 (Hamrick 2004), and the loss of Araucaria forest can cause an irreversible loss of species of

568 high conservation and functional importance.

In summary, both habitat type and daily period of activity drive dung beetle

570 composition, abundance, functional richness, and functional diversity. Average ambient

571 temperatures also influence dung beetle abundance and functional divergence. There is an

572 increase in functional richness along the open-closed gradient in the mountainous landscape,

573 but the functional divergence is higher in open habitats during the day and in closed habitats

574 at night. Spatially, there is high taxonomic species turnover, while nestedness predominates

575 temporally. For functional divergence, both turnover and nestedness are equally important. In

576 the near future, microclimatic conditions may be affected as much by the change in land use

577 as by climate change (Pyke 2004). Due to the probable increase in average temperatures

578 because of climate warming in all environments including closed habitats, the prevalence of a

579 high functional diversity assemblage of dung beetles at night, plus the buffering effect

580 provided by closed habitats, forest-dependent species are expected to experience low effects

581 due to climate warming per se. However, since changes in land use are driven by both

582 socioeconomic and climatic factors (Oliver \& Morecroft 2014), and the predicted future

583 scenario of Araucaria forest is quite pessimistic (Wrege et al. 2017), the interaction between

584 climate and human land use can cause pronounced negative effects in forest-dependent

585 species inhabiting high elevation forests if their habitat is drastically changed or lost. 
587

588

589

590

591 National Park, Santa Catarina State, southern Brazil.

592 Table S2. Dung beetle species sampled in five land uses for two days (D) and two nights (N)

593 in the São Joaquim National Park, Brazil. Land uses: grassland (GR), shrubland (SH),

594

595

596

597

598

599

600

601

602 References

603 Aguilar-Amuchastegui N. \& Henebry G. M. (2007) Assessing sustainability indicators for 604 tropical forests: Spatio-temporal heterogeneity, logging intensity, and dung beetle 605 communities. For. Ecol. Manage. 253, 56-67.

606 Amore V., Hernández M. I. M., Carrascal L. M. et al. (2017) Exoskeleton may influence the 607 internal body temperatures of Neotropical dung beetles (Col. Scarabaeinae). PeerJ 5, e3349. 608 Anderson M. J. (2001) A new method for non-parametric multivariate analysis of variance. 609

\section{Supporting Information} agroforest (AG), secondary forest (SF), and primary forest (PF). T: Total; TG: total general. Figure S1. Distribution of temperature variables among land uses for ambient and soil. Land uses: grassland (GR), shrubland (SH), agroforest (AG), secondary forest (SF), and primary forest (PF). Since there are four measures for each land use, the day values are above the median, while the night values are below the median.

Figure S2. Dissimilarity of Jaccard (a) and beta diversity partitioning into turnover (darker circles) and nestedness (lighter circles) (b) versus geographic distance among land uses. Austral Ecol. 26, 32-46. 
610 Arellano L., Favila M. E. \& Huerta C. (2005) Diversity of dung and carrion beetles in a

611 disturbed Mexican tropical montane cloud forest and on shade coffee plantations. Biodivers.

612 Conserv. 14, 601-15.

613 Barragan F., Moreno C. E., Escobar F. et al. (2011) Negative impacts of human land use on

614 dung beetle functional diversity. PLOS ONE 6, e17976.

615 Baselga A. (2010) Partitioning the turnover and nestedness components of beta diversity.

616 Glob. Ecol. Biogeogr. 19, 134-43.

617 Baselga A. \& Orme C. D. L. (2012) betapart: an R package for the study of beta diversity.

618 Methods Ecol. Evol. 3, 808-12.

619 Bates D., Maechler M., Bolker B. et al. (2015) Fitting linear mixed-effects models using 620 lme4. J. Stat. Softw. 67, 1-48.

621 Batilani-Filho M. \& Hernández M. I. M. (2017) Decline of ecological functions performed by 622 dung beetles in areas of Atlantic Forest and contribution of rollers and tunnellers in organic 623 matter removal. Environ. Entomol. 46, 784-93.

624 Behling H., Pillar V. D., Orlóci L. et al. (2004) Late Quaternary Araucaria forest, grassland 625 (Campos), fire and climate dynamics, studied by high-resolution pollen, charcoal and 626 multivariate analysis of the Cambará do Sul core in southern Brazil. Palaeogeogr. 627 Palaeoclimatol. Palaeoecol. 203, 277-97.

628 Boldrini I. I. (2009) Introdução. In: Biodiversidade dos campos do planalto das araucárias 629 (ed I. I. Boldrini) pp. 7-11. MMA, Brasília, DF.

630 Braga R. F., Korasaki V., Andresen E. et al. (2013) Dung beetle community and functions 631 along a habitat-disturbance gradient in the Amazon: a rapid assessment of ecological 632 functions associated to biodiversity. PLOS ONE 8, e57786.

633 Brook B. W., Ellis E. C., Perring M. P. et al. (2013) Does the terrestrial biosphere have 634 planetary tipping points? Trends Ecol. Evol. 28, 396-401. 
635 Chao A. (1984) Nonparametric estimation of the number of classes in a population. 636 Scandinavian Journal of Statistics 11, 265-70.

637 Chou S. C., Lyra A., Mourão C. et al. (2014) Assessment of Climate Change over South 638 America under RCP 4.5 and 8.5 Downscaling Scenarios. Am. J. Clim. Change 3, 512-25.

639 da Silva P. G. (2017) Dung beetles (Coleoptera, Scarabaeinae) from high altitude grasslands 640 in São Joaquim National Park, Santa Catarina, southern Brazil. Check List 13, 817-30.

641 da Silva P. G. \& Hernández M. I. M. (2014) Local and regional effects on community 642 structure of dung beetles in a mainland-island scenario. PLOS ONE 9, e111883.

643 da Silva P. G. \& Hernández M. I. M. (2015a) Scale-dependence of processes structuring dung 644 beetle metacommunities using functional diversity and community deconstruction 645 approaches. PLOS ONE 10, e0123030.

646 da Silva P. G. \& Hernández M. I. M. (2015b) Spatial patterns of movement of dung beetle 647 species in a tropical forest suggest a new trap spacing for dung beetle biodiversity studies. $648 \quad$ PLOS ONE 10, e0126112.

649 da Silva P. G., Lobo J. M., Hensen M. C. et al. (2018) Turnover and nestedness in subtropical 650 dung beetle assemblages along an elevational gradient. Divers. Distrib. in press, 1-14.

651 da Silva P. G., Vaz-de-Mello F. Z. \& Di Mare R. A. (2013) Diversity and seasonality of 652 Scarabaeinae (Coleoptera: Scarabaeidae) in forest fragments in Santa Maria, Rio Grande do 653 Sul, Brazil. An. Acad. Bras. Cienc. 85, 679-97.

654 de Bello F., Carmona C. P., Mason N. W. H. et al. (2013) Which trait dissimilarity for 655 functional diversity: trait means or trait overlap? J. Veg. Sci. 24, 807-19.

656 de Bello F., Lavergne S., Meynard C. N. et al. (2009) The partitioning of diversity: showing 657 Theseus a way out of the labyrinth. J. Veg. Sci. 21, 992-1000. 
658 Escobar F., Halffter G., Solís Á. et al. (2008) Temporal shifts in dung beetle community 659 structure within a protected area of tropical wet forest: a 35-year study and its implications for 660 long-term conservation. J. Appl. Ecol. 45, 1584-92.

661 Feer F. \& Pincebourde S. (2005) Diel flight activity and ecological segregation within an 662 assemblage of tropical forest dung and carrion beetles. J. Trop. Ecol. 21, 21-30.

663 Frey S. J. K., Hadley A. S., Johnson S. L. et al. (2016) Spatial models reveal the 664 microclimatic buffering capacity of old-growth forests. Science Advances 2, e1501392.

665 Gallego B., Verdú J. R. \& M. L. J. (2018) Comparative thermoregulation between different 666 species of dung beetles (Coleoptera: Geotrupinae). J. Therm. Biol. 74, 84-91.

667 Gardner T. A., Hernández M. I. M., Barlow J. et al. (2008) Understanding the biodiversity 668 consequences of habitat change: the value of secondary and plantation forests for neotropical 669 dung beetles. J. Appl. Ecol. 45, 883-93.

670 Geiger R., Aron R. H. \& Todhunter P. (2003) The Climate Near the Ground. Rowman \& 671 Littlefield Publishers, Lanham.

672 Giménez-Gómez V. C., Lomáscolo S. B., Zurita G. A. et al. (in press) Daily activity patterns 673 and thermal tolerance of three sympatric dung beetle species (Scarabaeidae: Scarabaeinae: 674 Eucraniini) from the Monte Desert, Argentina. Neotrop. Entomol., 1-7.

675 Gómez-Cifuentes A., Munevar A., Gimenez V. C. et al. (2017) Influence of land use on the 676 taxonomic and functional diversity of dung beetles (Coleoptera: Scarabaeinae) in the southern 677 Atlantic forest of Argentina. J. Insect Conserv. 21, 147-56.

678 Halffter G. \& Edmonds W. D. (1982) Nesting behavior of dung beetles (Scarabaeinae). Man 679 and Biosphere Program - UNESCO, Mexico, D. F.

680 Hamrick J. L. (2004) Response of forest trees to global environmental changes. For. Ecol. $681 \quad$ Manage. 197, 323-35.

682 Hanski I. \& Cambefort Y. (1991) Dung beetle ecology. Princeton University Press, Princeton. 
683 Hernández M. I. M. (2002) The night and day of dung beetles (Coleoptera, Scarabaeidae) in 684 the Serra do Japi, Brazil: elytra colour related to daily activity. Rev. Bras. Entomol. 46, 597685600.

686 Hernández M. I. M. \& Vaz-de-Mello F. Z. (2009) Seasonal and spatial species richness 687 variation of dung beetle (Coleoptera, Scarabaeidae s. str.) in the Atlantic Forest of 688 southeastern Brazil. Rev. Bras. Entomol. 53, 607-13.

689 Hsieh T. C., Ma K. H., Chao A. et al. (2016) iNEXT: an R package for rarefaction and 690 extrapolation of species diversity (Hill numbers). Methods Ecol. Evol. 7, 1451-6.

691 Hutchinson G. E. (1957) Concluding Remarks. Cold Spring Harbor Symp. Quant. Biol. 22, $692 \quad 415-27$.

693 Iannuzzi L., Salomão R. P., Costa F. C. et al. (2016) Environmental patterns and daily activity 694 of dung beetles (Coleoptera: Scarabaeidae) in the Atlantic Rainforest of Brazil. 695 Entomotropica 31, 196-207.

696 Jetz W., Wilcove D. S. \& Dobson A. P. (2007) Projected Impacts of climate and land-use 697 change on the global diversity of birds. PLoS. Biol. 5, e157.

698 Jost L. (2007) Partitioning diversity into independent alpha and beta components. Ecology 88, $699 \quad 2427-39$.

700 Klein B. C. (1989) Effects of forest fragmentation on dung and carrion beetle communities in

701 Central Amazonia. Ecology 70, 1715-25.

702 Koskela H. (1979) Patterns of diel flight activity in dung-inhabiting beetles: an ecological 703 analysis. Oikos 33, 419-39.

704 Krell-Westerwalbesloh S., Krell F. T. \& Linsenmair E. (2004) Diel separation of Afrotropical 705 dung beetle guilds-avoiding competition and neglecting resources (Coleoptera: 706 Scarabaeoidea). J. Nat. Hist. 38, 2225-49. 
707 Krell F. T., Krell-Westerwalbesloh S., Weiß I. et al. (2003) Spatial separation of Afrotropical 708 dung beetle guilds: a trade-off between competitive superiority and energetic constraints 709 (Coleoptera: Scarabaeidae). Ecography 26, 210-22.

710 Laliberté E. \& Legendre P. (2010) A distance-based framework for measuring functional 711 diversity from multiple traits. Ecology 91, 299-305.

712 Laliberté E., Legendre P. \& Shipley B. (2014) FD: measuring functional diversity from 713 multiple traits, and other tools for functional ecology. R package version 1.0-12.

714 Landin B. O. (1968) The diel flight activity of dung-beetles (Coleoptera Scarabaeidae). A 715 study of the influence of environmental factors, with particular reference to the light. 716 Entomologiska Sällskapet, Lund.

717 Legendre P. \& Legendre L. (2012) Numerical Ecology. Elsevier, Amsterdam.

718 Liberal C. N., Farias Â. M. I., Meiado M. V. et al. (2011) How habitat change and rainfall 719 affect dung beetle diversity in Caatinga, a Brazilian semi-arid ecosystem. J. Insect Sci. 11, 720114.

721 Lobo J. M. \& Halffter G. (2000) Biogeographical and ecological factors affecting the 722 altitudinal variation of mountainous communities of coprophagous beetles (Coleoptera: 723 Scarabaeoidea): a comparative study. Ann. Entomol. Soc. Am. 93, 115-26.

724 Lobo J. M., Lumaret J. P. \& Jay-Robert P. (1998) Sampling dung beetles in the French 725 Mediterranean area: effects of abiotic factors and farm practices. Pedobiologia 42, 252-66.

726 Lopes J., Korasaki V., Catelli L. L. et al. (2011) A comparison of dung beetle assemblage 727 structure (Coleoptera: Scarabaeidae: Scarabaeinae) between an Atlantic forest fragment and 728 adjacent abandoned pasture in Paraná, Brazil. Zoologia 28, 72-9.

729 Mello A. J. M. \& Peroni N. (2015) Cultural landscapes of the Araucaria Forests in the 730 northern plateau of Santa Catarina, Brazil. J. Ethnobiol. Ethnomed. 11, 51. 
731 Nichols E., Larsen T., Spector S. et al. (2007) Global dung beetle response to tropical forest

732 modification and fragmentation: A quantitative literature review and meta-analysis. Biol.

733 Conserv. 137, 1-19.

734 Nichols E., Spector S., Louzada J. et al. (2008) Ecological functions and ecosystem services

735 provided by Scarabaeinae dung beetles. Biol. Conserv. 141, 1461-74.

736 Nunes C. A., Braga R. F., Figueira J. E. et al. (2016) Dung beetles along a tropical altitudinal 737 gradient: environmental filtering on taxonomic and functional diversity. PLoS ONE 11, $738 \mathrm{e} 0157442$.

739 Oksanen J., Blanchet F. G., Friendly M. et al. (2016) Vegan: community ecology package. R 740 package version 2.4-1.

741 Oliver T. H. \& Morecroft M. D. (2014) Interactions between climate change and land use 742 change on biodiversity: attribution problems, risks, and opportunities. WIREs Climate Change $743 \mathbf{5}, 317-35$.

744 Peyras M., Vespa N. I., Bellocq I. et al. (2013) Quantifying edge effects: the role of habitat 745 contrast and species specialization. J. Insect Conserv. 17, 807-20.

746 Pyke C. R. (2004) Habitat loss confounds climate change impacts. Front. Ecol. Environ 2, $747 \quad 178-82$.

748 Scheffler P. Y. (2005) Dung beetle (Coleoptera: Scarabaeidae) diversity and community

749 structure across three disturbance regimes in eastern Amazonia. J. Trop. Ecol. 21, 9-19.

750 Scholtz C. H., Davis A. L. V. \& Kryger U. (2009) Evolutionary biology and conservation of 751 dung beetles. Pensoft Publishers, Sofia.

752 Schowalter T. D. (2011) Insect ecology: an ecosystem approach. Elsevier, Burlington.

753 Slade E. M., Mann D. J., Villanueva J. F. et al. (2007) Experimental evidence for the effects

754 of dung beetle functional group richness and composition on ecosystem function in a tropical 755 forest. J. Anim. Ecol. 76, 1094-104. 
756 Solar R. R., Barlow J., Ferreira J. et al. (2015) How pervasive is biotic homogenization in 757 human-modified tropical forest landscapes? Ecol. Lett. 18, 1108-18.

758 Suggitt A. J., Gillingham P. K., Hill J. K. et al. (2011) Habitat microclimates drive fine-scale 759 variation in extreme temperatures. Oikos 120, 1-8.

760 Tittensor D. P., Walpole M., Hill S. L. L. et al. (2014) A mid-term analysis of progress 761 toward international biodiversity targets. Science 346, 241-4.

762 Vaz-de-Mello F. Z., Leivas F. W. T. \& Grossi P. C. (2014) Scarabaeoidea (Coleoptera: 763 Polyphaga) do Parque Nacional de São Joaquim - PNSJ, Santa catarina, Brasil. In: Parque 764 Nacional de São Joaquim - Portal do Conhecimento (eds P. V. Castilho, M. T. R. N. Omena 765 and M. H. Tanivaki) pp. 115-34. Ed. Santarém, São Paulo.

766 Verdú J. R., Arellano L. \& Numa C. (2006) Thermoregulation in endothermic dung beetles 767 (Coleoptera: Scarabaeidae): effect of body size and ecophysiological constraints in flight. $J$. 768 Insect Physiol. 52, 854-60.

769 Verdú J. R., Díaz A. \& Galante E. (2004) Thermoregulatory strategies in two closely related 770 sympatric Scarabaeus species (Coleoptera: Scarabaeinae). Physiol. Entomol 29, 32-8.

771 Villéger S., Mason N. W. H. \& Mouillot D. (2008) New multidimensional functional 772 diversity indices for a multifaceted framework in functional ecology. Ecology 89, 2290-301.

773 Wrege M. S., Fritzsons E., Soares M. T. S. et al. (2017) Distribuição natural e habitat da 774 araucária frente às mudanças climáticas globais. Pesq. Flor. Bras. 37, 331-46.

775 Wrege M. S., Sousa V. A., Fritzsons E. et al. (2016) Predicting current and future 776 geographical distribution of Araucaria niche modeling. Environ. Ecol. Res. 4, 269-79. 
Table 1. Effect of site, daily period, their interaction, and climatic variables on each dung beetle response variable (richness, abundance, functional richness [FRic], and functional divergence [Rao's Q]). Results are based on generalized linear mixed models using repeated measures of traps along daily periods in each site. The chi-square tests were used for richness, abundance, and functional richness, while the $F$ test was used for Rao's $Q$. The climatic variables of minimum ambient temperature ( $\left.\mathrm{T}^{\mathrm{a}}{ }_{\mathrm{Mamb}}\right)$, maximum soil temperature $\left(\mathrm{T}^{\mathrm{a}}{ }_{\mathrm{MSoil}}\right)$, and precipitation are used as co-variables. ${ }^{*} \mathrm{p}<0.01,{ }^{*} \mathrm{p}<0.001,{ }^{*} * \mathrm{p}<0.0001$

\begin{tabular}{lcccccc}
\hline & Site & Period & Site*Period & $\mathbf{T}^{\mathrm{a}}{ }^{*} \mathbf{a m b}$ & $\mathbf{T}^{\mathrm{a}}{ }_{\mathrm{M}}$ soil & Precipitation \\
& $\mathbf{d f}(\mathbf{4}, \mathbf{8 7})$ & $\mathbf{d f}(\mathbf{1}, \mathbf{8 7})$ & $\mathbf{d f}(\mathbf{4}, \mathbf{8 7})$ & $\mathbf{d f}(\mathbf{1}, \mathbf{8 7})$ & $\mathbf{d f}(\mathbf{1}, \mathbf{8 7})$ & $\mathbf{d f}(\mathbf{1}, \mathbf{8 7})$ \\
\hline Richness & $5.771^{\mathrm{NS}}$ & $4.489^{*}$ & $7.458^{\mathrm{NS}}$ & $2.636^{\mathrm{NS}}$ & $0.194^{\mathrm{NS}}$ & $0.219^{\mathrm{NS}}$ \\
Abundance & $14.272^{*}$ & $3.399^{\mathrm{NS}}$ & $49.057^{* * *}$ & $12.483^{* *}$ & $0.593^{\mathrm{NS}}$ & $0.087^{\mathrm{NS}}$ \\
FRic & $21.972^{* * *}$ & $0.014^{\mathrm{NS}}$ & $13.348^{* *}$ & $0.700^{\mathrm{NS}}$ & $0.039^{\mathrm{NS}}$ & $1.035^{\mathrm{NS}}$ \\
Rao's Q & $45.891^{* * *}$ & $6.724^{\mathrm{NS}}$ & $211.149^{* * *}$ & $67.597^{* * *}$ & $0.266^{\mathrm{NS}}$ & $2.201^{\mathrm{NS}}$ \\
\hline
\end{tabular}


1 Fig. 1 Richness (median and quartiles) of dung beetles by daily periods. Dots represent

2 species richness for each trap regardless of the site (see Table 1).

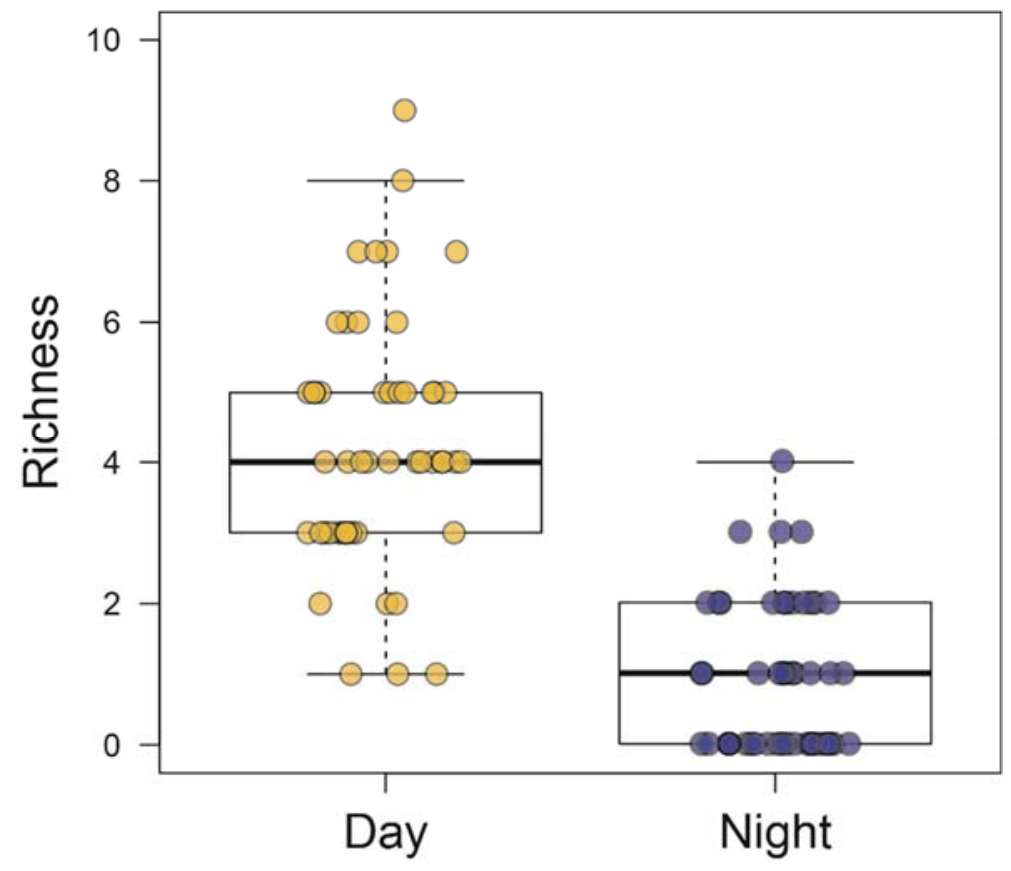

4 
5 Fig. 2 Results of GLMM models showing the adjusted means ( $\pm 95 \% \mathrm{CI})$ of the response

6 variables for which the interaction term "sampling sites $\mathrm{x}$ daily periods) is statistically

7 significant (see Table 1). Adjusted means derived from GLMM models controlling for the

8 effects of the selected climatic variables. Night $=$ circles, Day $=$ squares.

9
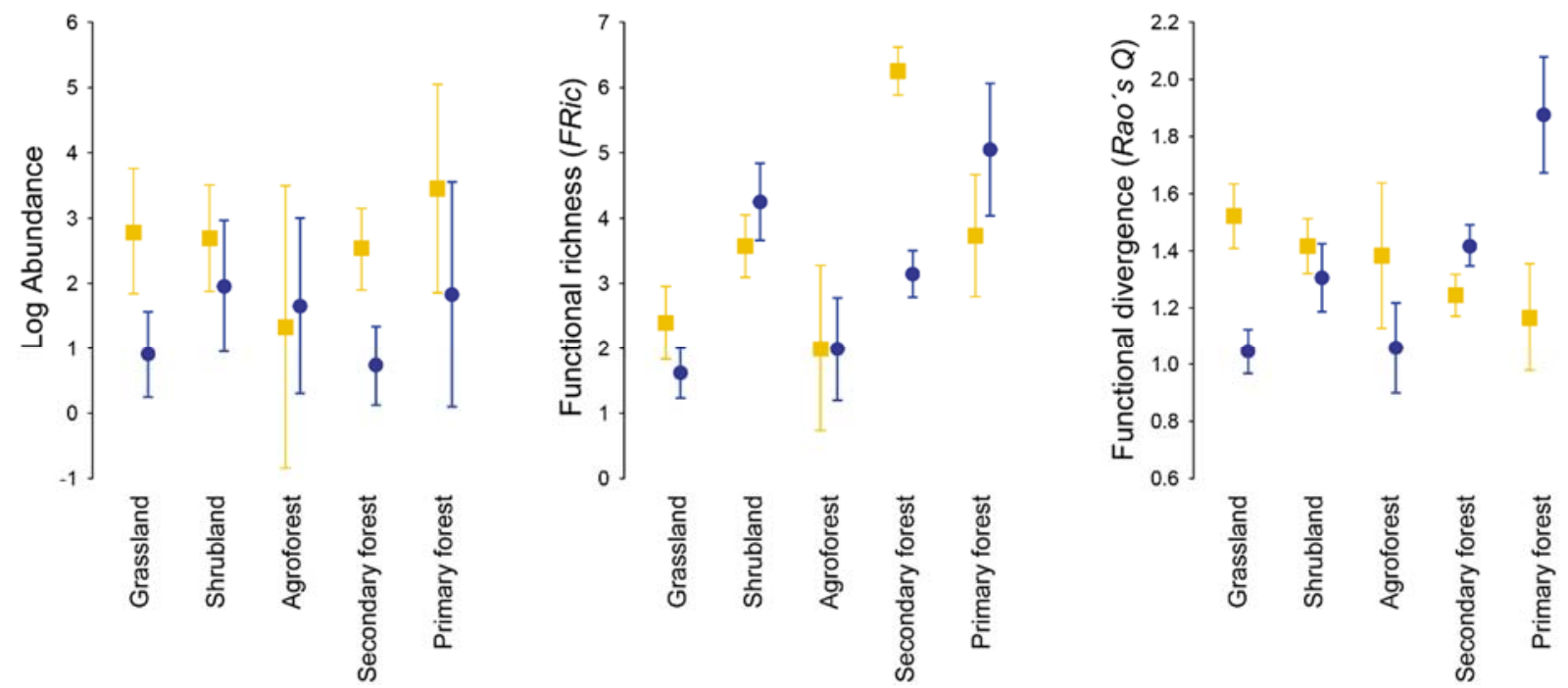

10 
11 Fig. 3 Dung beetle composition among the five sampling sites during the day and night

12 periods. Sites: grassland (GR), shrubland (SH), agroforest (AG), secondary forest (SF), and 13 primary forest (PF).

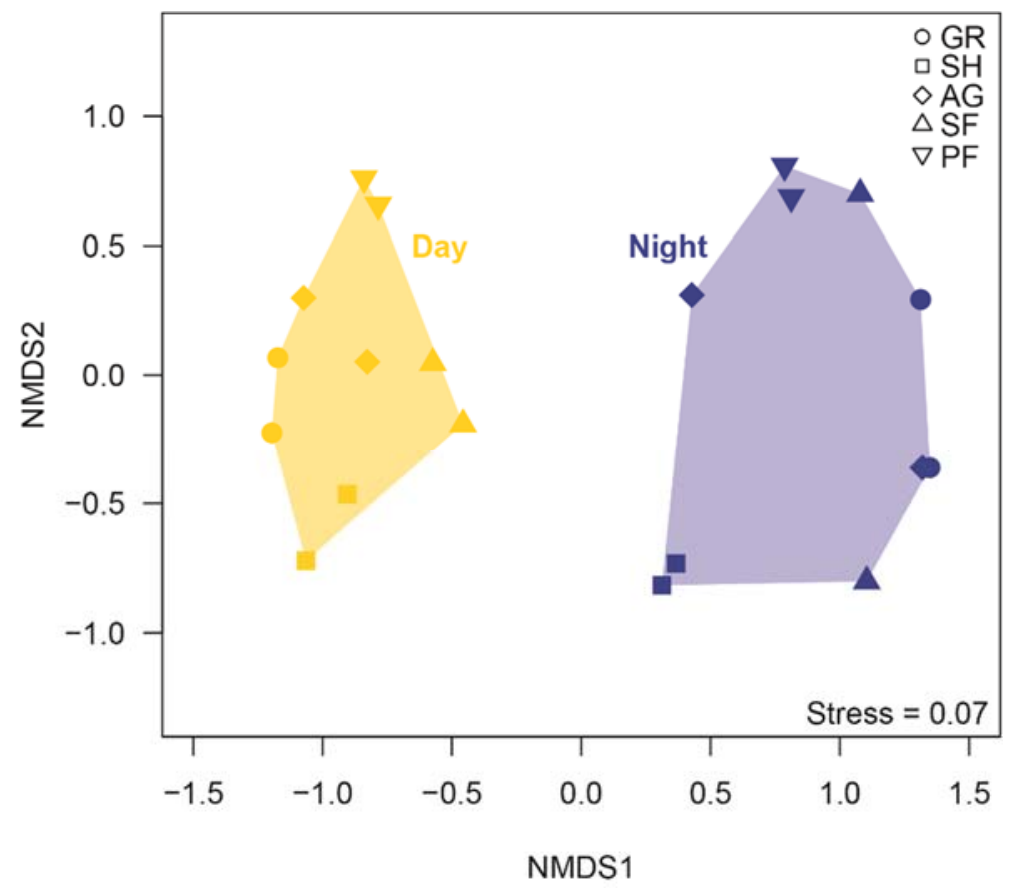

15 
16 Fig. 4 Taxonomic (a-b) and functional (c-d) diversity partitioning $(\alpha, \beta, \gamma)$ among spatial (land

17 uses; spa) and temporal (sampling periods; tem) scales (a,c), and $\beta$ diversity partitioning into

18 its turnover (turn) and nestedness-related (nest) components (b,d). Asterisks indicate

19 statistical differences between observed (Obs) and expected (Exp) values (left panels).

20 Taxonomic and functional $\beta$ diversities were partitioned into turnover and nestedness

21 components spatially and temporally.

(a)

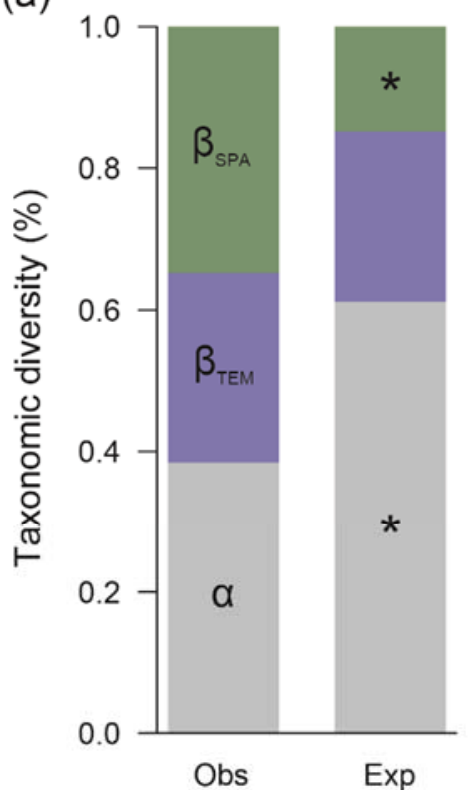

(c)

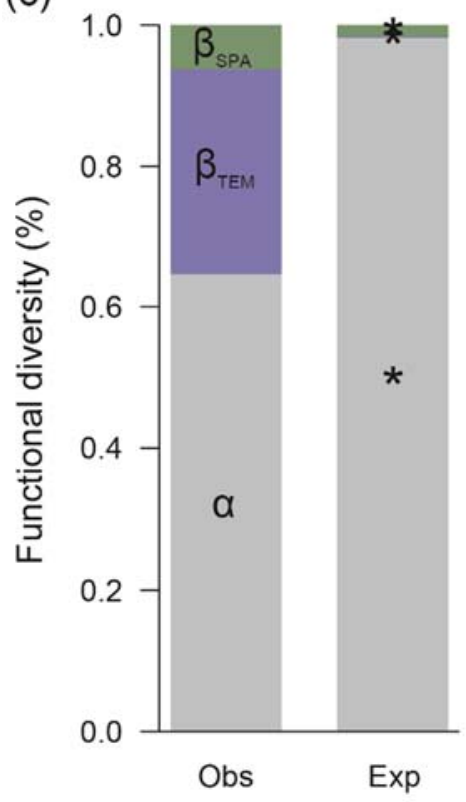

(b)

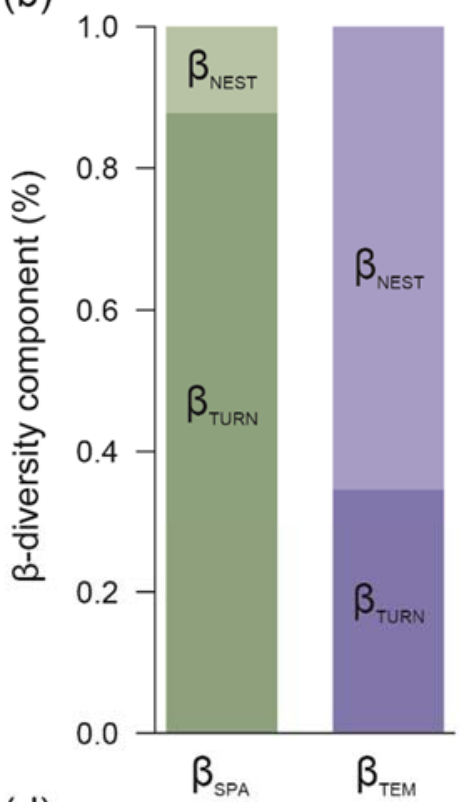

(d)

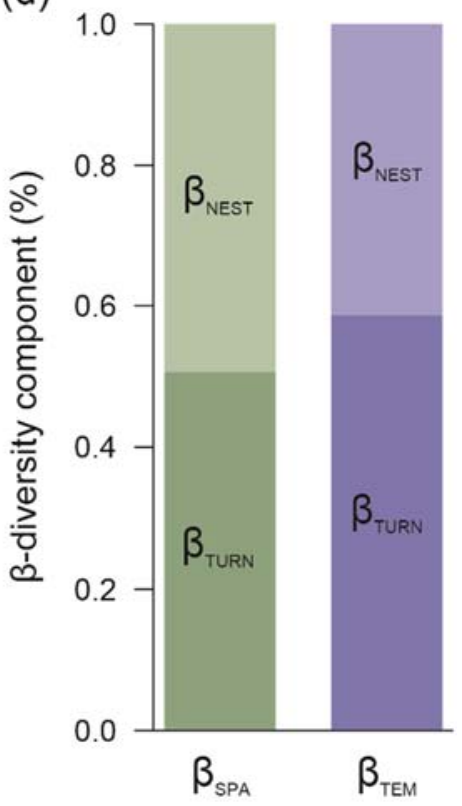

